\title{
Role of Crush Cytology in Intraoperative CNS Tumors
}

\author{
Dr. Sangeeta Yadav ${ }^{1 *}$, Dr. Surabhi Tyagi ${ }^{2}$, Dr. B.S.Sharma ${ }^{3}$
}

${ }^{1}$ 2nd Yr. P.G student, ${ }^{2}$ Professor Neuropathology, ${ }^{3}$ Professor \& HOD Neurosurgery, Mahatma Gandhi Medical University, Jaipur, India

DOI: $\underline{10.36347 / \text { sjmcr.2020.v08i01.012 }}$

| Received: 05.01.2020 | Accepted: 12.01.2020 | Published: 17.01.2020

*Corresponding author: Dr. Sangeeta Yadav

\section{Abstract}

Aims \& objective: To assess the efficiency of intraoperative crush cytology and its correlation with histopathological diagnosis. Methods: The patient was investigated by various radiological \& lab tests and operated. Intraoperative crush cytology smear was prepared, stained by rapid H\& E method \& later correlated with the histopathological diagnosis of the biopsy received. Result: The intraoperative cytological diagnosis was the same as the histopathological diagnosis including the grade of the tumor. Conclusion: Crush cytology is the only possible way for rapid \& reliable diagnosis of intra- cranial space occupying lesions as FNAC cannot be performed in the cranial cavity. It has a high accuracy rate \& avoids the freezing artifacts of the frozen section

Keywords: Central nervous system tumors, intraoperative diagnosis, squash preparation.

Copyright @ 2020: This is an open-access article distributed under the terms of the Creative Commons Attribution license which permits unrestricted use, distribution, and reproduction in any medium for non-commercial use (NonCommercial, or CC-BY-NC) provided the original author and source are credited.

\section{INTRODUCTION}

Making the diagnosis of CNS lesions is difficult on the basis of clinical and radiological findings only. Cytological \& histological diagnosis is required for confirmation and proper management. Fine needle aspiration of intracranial space occupying lesions is difficult due to the closed architecture .Crush cytology is the only possible way to provide a rapid \& reliable diagnosis .Role of intraoperative pathological diagnosis is crucial in neurosurgery helping the neurosurgeon to plan the extent of surgery and modify it accordingly .Besides rapid decision making during neurological procedures it is also ensured that minimum injury is caused to the normal brain structures surrounding the intracranial neoplasm,

\section{AIMS \& OBJECTIVE}

To assess the efficiency of intraoperative crush cytology and its correlation with histopathological diagnosis

\section{Case Report}

A 60 years old patient came to the neurosurgery OPD with complaints of headache \& seizures. On MRI examination left frontal multiple space occupying lesions were present.

Intraoperative-Tumor was soft, suckable, grayish, moderately vascular, reaching up to surface with no clear planes of differentiation with cystic component.

Crush cytology- Smears studied were hypercellular showing astrocytic tumor cells with moderate to marked nuclear atypia with many bizarre forms in a fibrillary background. Fair number of multinucleated giant cells, brisk mitotic activity, microfoci of necrosis and vascular proliferation were present.

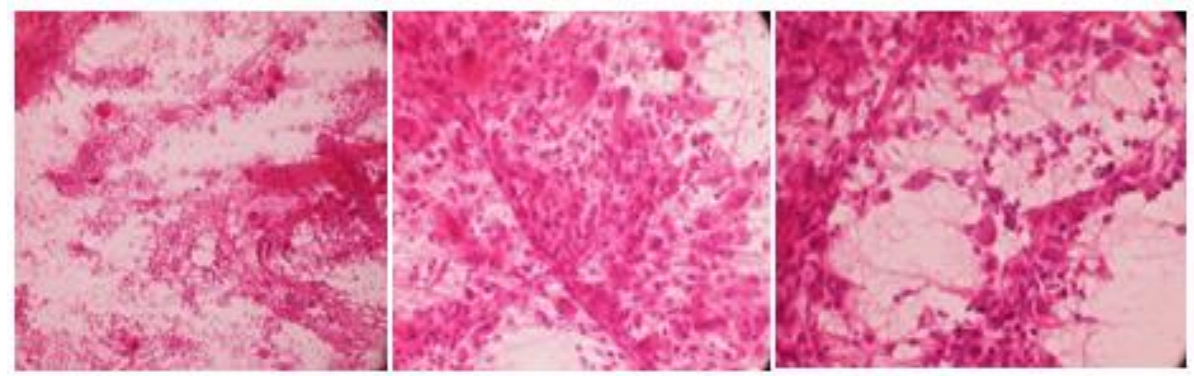


Impression-Cytomorphologically features were suggestive of a high grade glioma- possibility of glioblastoma was suggested.

Frozen sections- Specimen sent for frozen section show tumor tissue with features

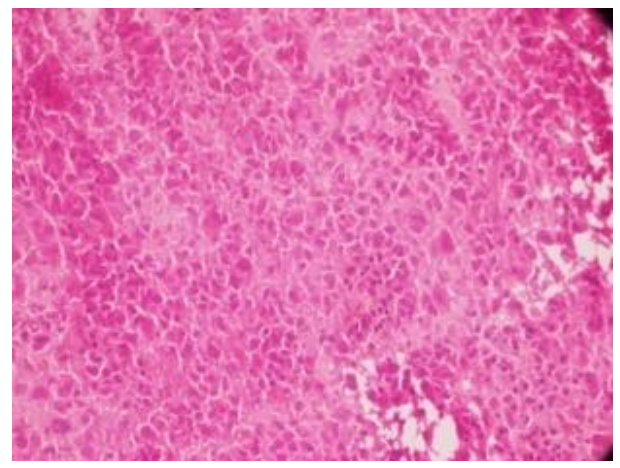

\section{Suggestive of a high grade glioma}

Gross examination- Formalin fixed specimen consists of several grey white to grey brown soft tissue pieces collectively measuring $1.2 \mathrm{X} 0.5 \mathrm{~cm}$.

Paraffin embedded sections -Sections studied show a highly cellular glioma with astrocytic differentiation. Moderate to marked nuclear atypia is seen with bizarre forms and multinucleated giant cells. Brisk mitotic activity, microvascular 'glomeroid' proliferation and palisading "serpentine" necrosis is seen.

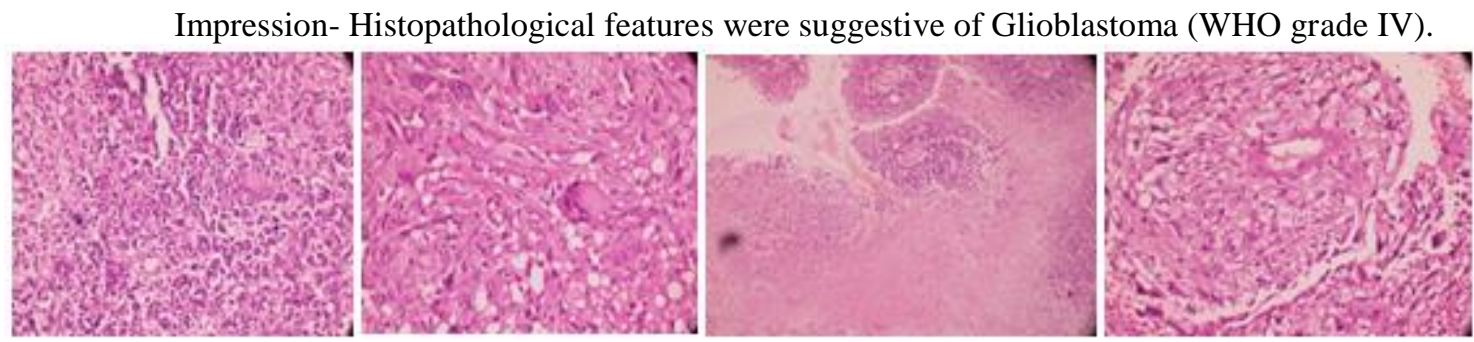

$$
\begin{gathered}
\text { Immunomarkers for IDH mutation status - } \\
\text { IDH mutant } \\
\text { ATRX retained } \\
\text { P53 positive } \\
\text { MIB1 }=10-12 \% \text { in highest proliferating areas. }
\end{gathered}
$$

Therefore, it was reported as IDH mutant Glioblastoma. MGMT status - methylated.

\section{DISCUSSION}

Squash/crush cytology is a simple and rapid method which provides good cellular details in minimal time and devoid of freezing artifacts occurring in the frozen sections. In our case there was good cytological and histological correlation.

The goal of a pathologist in intraoperative setting is not to diagnose and grade every case definitively, rather to provide sufficient preliminary information to optimize surgery. A brain tissue is soft and with high water content is renders poor quality frozen sections and thus crush cytology is more conclusive for opinion.

A precise diagnosis however, requires good correlation of clinical, radiological and histopathological data.

\section{CONCLUSION}

Crush cytology / squash cytology is fairly accurate, simple and cost effective tool for rapid diagnosis in CNS lesions and it gives good cellular detail and even avoids freezing artifacts. However correlation with clinical data as well as radiological CT $\&$ MRI findings increases the diagnostic accuracy.

\section{REFERENCES}

1. Roessler K, Dietrich W, Kitz K. High diagnostic accuracy of cytologic smears of central nervous system tumors. A 15-year experience based on 4,172 patients. Acta Cytol. 2002; 46:667-74.

2. Shah AB, Muzumdar GA, Chitale AR, Bhagwati $\mathrm{SN}$. Squash preparation and frozen section in intraoperative diagnosis of central nervous system tumors. Acta Cytol. 1998; 42:1149-54.

3. Iqbal M, Shah A, Wani MA, Kirmani A, Ramzan A. Cytopathology of the central nervous system. Part I. Utility of crush smears cytology in intraoperative diagnosis of central nervous system lesions. Acta Cytol. 2006; 50:608-16.

4. Mouriquand C, Benabid AL, Breyton M. Stereotaxic cytology of brain tumors. Review of an eight-year experience. Acta Cytol. 1987;31:756-64

5. Adams JH, Graham DI, Doyle D. London: Chapman and Hall; 1981. Brain Biopsy: the smear technique for neurosurgical biopsies; pp. 11-4. 